\title{
Homogeneous / Heterogeneous Structure and Forms of Dialectics
}

\author{
Bahar Gokcen Kumsar ${ }^{1}$ \\ ${ }^{1}$ Architect / Research Assistant Istanbul Technical University
}

Email:bgkumsar@gmail.com

\begin{abstract}
The notion of utopia which is came from ancient to the present day in a historical perspective as an unreal place and which is intended to reach to perfection by the effect of social realities could not provide the critical environment necessitated for the 20th-century problems. Patriarchy, capitalism, colonialism and other realities which hold on in historical perspective touch the formations of gender, race or class consciousness off around feminist theory, and they make them the focus of the epoch. The narratives of the late 20th century rather than search for the ideal, achieve perfection, they destroy all positions not only search for those who are different from all positions but also aim to create a critical environment by seeing the irreducible together.

Michel Foucault draws attention to fantastic, untroubled and homogeneous structure of the concept of utopia and liken utopias to the flowing order with the distinctive features of the language. The late 20th century formations and the environment required by these formations are expressed as the desire to construct polyphonic, heterogeneous environments and he defines these environments as heterotopia. If the narratives of the ancient period are discussed through the concept of utopia, the narratives of the late 20th century are discussed through the concept of heterotopia that is a new formation pointed out by Foucault, the texts of different periods which exhibit structurally very different positions (homogeneous and heterogeneous) are structured by collaborating on dialectical thinking. Dialectical thought continues to exist on the basis of the way of thinking both in the late 20th century narratives and in ancient texts. Getting a foothold of vague, ambiguous, transient forms which exist in the environment to human thoughts provides clues about dialectics. The human creates a series of binary oppositions, during thinking in order to find meaning in it with the motivation of rationalization. This study aims to trace different forms of dialectical thought through the texts of the different epoch (homogeneous / heterogeneous), which exhibited very different stances from each other.
\end{abstract}

Considering the structural differences between antiquity and late 20th century texts, how do the limitlessness and limits of dialectical thought between binaries play a role in the construction of these differences (homogeneous/ heterogeneous)? For highlighting these differences, the narrative of The Republic of Plato as a homogeneous text is examined comparatively with the late 20th-century heterogeneous text of Triton with regard to fictionalizing dialectics over sex / gender binary opposition which is the notional focus of the late 20th-century.

(C) 2019 The Authors. Published by IEREK press. This is an open access article under the CC BY license (https://creativecommons.org/licenses/by/4.0/).

\section{Keywords}

the ethic of care for the self; utopia; heterotopia; homogeneous/heterogeneous; sex/gender; dialectic contradiction 


\section{Introduction}

\subsection{Homogeneous/Heterogeneous Structure}

The narratives of the antique epoch aim to reach the ideal one as a perfect around subjectivity and truth (ethics) relationship. Social life is organized around the determined ethics in order to reach the ideal. In the late 20th century texts, patriarchy, capitalism, colonialism and other realities which hold on in historical perspective touch the formations of gender, race or class consciousness off around feminist theory, and they make them the focus of the epoch. There has been a risk of classification against poetic/political integrity for the history of feminism in the process of examining formations, with the effect of political tendencies; as the radical, liberal, socialist types. Donna J. Haraway has built a model around sex activity where two tendencies could coexist without being stuck to the concepts of gender (radical feminism) or labor (socialist feminism). This model seeks to construct an ironic myth around feminism, socialism and materialism. "Irony is about contradictions that do not resolve into larger wholes, even dialectically, about the tension of holding incompatible things together because both or all are necessary and true. Irony is about humor and serious play" (Haraway, 2006, p.117). The concept of utopia, which has no real place, not only intends to reach out to perfection or ideal but also fictionalizes the opposite one by the effect of social realities, can not be a definition for Haraway's ambiguous structure. Similarly, Michel Foucault has developed heterotopias as a model against utopias in order to fictionalize spaces that break down myths by preserving poetry and create ambiguous relationships by breaking down structures. He expresses the absolute differences between utopia and heterotopia as follows,

Utopias afford consolation: although they have no real locality there is nevertheless a fantastic, untroubled region in which they are able to unfold; they open up cities with vast avenues, superbly planted gardens, countries where life is easy, even though the road to them is chimerical. Heterotopias are disturbing, probably because they secretly undermine language, because they make it impossible to name this and that, because they shatter or tangle common names... (Foucault, 2005, p.19).

Utopias are homogeneous as they flow regularly, but the situation in which heterotopias and Haraway's quest for ironic myth fiction leads to the act of demolishing myths and heterogeneity (Figure 1).

The narratives of the late 20th century rather than search for the ideal, achieve perfection, they destroy all positions not only search for those who are different from all positions but also aim to create a critical environment by seeing the irreducible together. Structuralist attitude and feminist theory have contributed extemporally to these environments in historical development. According to Sandra Harding (1986), feminism can exist with at least double-seeing multiple subjects. It is free from a homogenous phenomenon that deals with critical views. Harding speaks of the three dimensions of gender that are gender symbolism, social-sexual division of labor and gender individual identity-building processes. Haraway, on the other hand, suggests that these three dimensions can establish mediated relations on the basis of a more fragmented structure (sex, gender, race, identity, etc.). In her determinations, which she termed situated knowledges, she seeks ways out of binary oppositions. She mentions that the terms conceal hierarchical duality. "Each binary opposition orders the silent term by a logic of appropriation, as resource to product, nature to culture, potential to actual. Both poles of opposition are constructed and structure each other dialectically" (for example, sex / gender binary opposition) (Haraway, 1988, p.599). In order to go out of these binary oppositions, she discovers a more fragmented structure and connection patterns by using the tension (contradiction) between them and reveals mediated relations.

Dialectical contradiction can be thought of as inspirational when looking for ways to go out of binary oppositions (terms) and exploring mediated relationships.

Getting a foothold of vague, ambiguous, transient forms which exist in the environment to human thoughts provides clues about dialectics. The human being creates a series of binary oppositions, which she/he finds meaningful with the rationalization motive. The condition of binary opposition shows a stronger meaning together in comparison with the sense of the notions alone (Moles, 2012). Dialectical thought continues to exist on the basis of the way of thinking both in the late 20th century narratives and in ancient texts. 
Considering the structural differences between antiquity and late 20th century texts, how do the limitlessness and limits of dialectical thought between binary oppositions play a role in the construction of these differences (homogeneous-heterogeneous)? In this study, the narrative of The Republic of Plato from the ancient epoch as a utopic text is examined comparatively with the late 20th century heterotopic text of Triton according to the ways of constructing dialectics within the scope of sex/gender binary opposition.

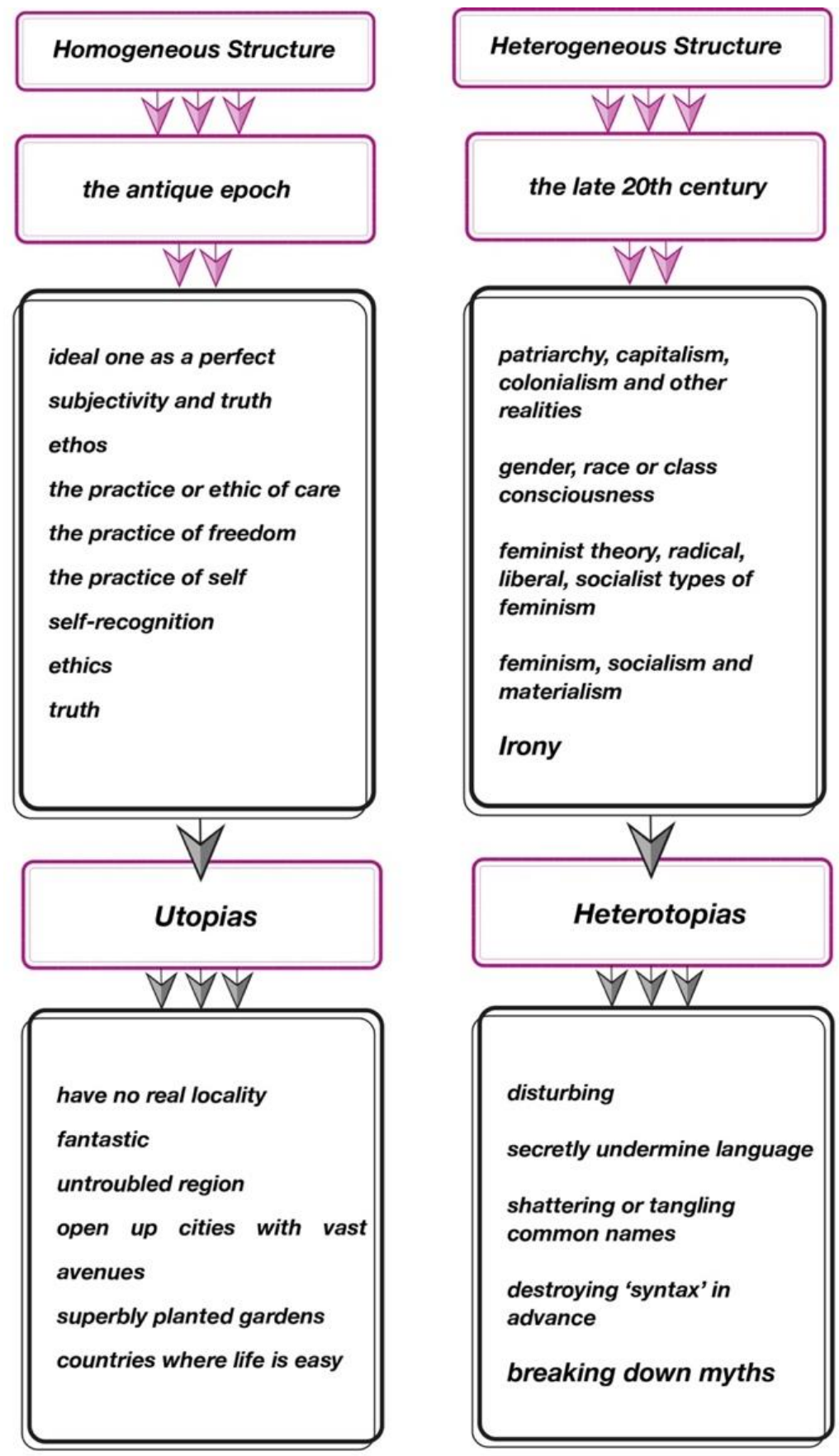

Figure 1. Homogeneous / heterogeneous structure (diagram by author)

\section{The Narrative of the Ancient Epoch The Republic of Plato and the Heterotopia of Late} 20th Century Triton

\subsection{Dialectical Contradiction/Relations}

In The Republic of Plato dialectic was portrayed as,

So, also, when a man tries by discussion — by means of argument without the use of any of the senses - to attain to each thing itself that is and doesn't give up before he grasps by intellection itself that which is good litself, he comes to the very end of the intelligible realm just as that other man was then at the end of the visible (Plato et al., book VII 532a, 1991, p. 211). 
...only the dialectical way of inquiry proceeds in this direction, destroying the hypotheses, to the beginning itself in order to make it secure; and when the eye of the soul is really buried in a barbaric bog, dialectic gently draws it forth and leads it up above, using the arts we described as assistants and helpers in the turning around (Plato et al., book VII 533d, 1991, p. 212).

In the narrative of The Republic of Plato, on the one part, it is spoken of the critical importance of dialectics, on the other side, it is mentioned that the dialectic between flatterers causes moral corruption. For this reason, people who will deal with dialectic are trained, selected, and measures are taken. The chosen ones do dialectical studies without being interested in anything else and these works are considered as the equivalent of gymnastics. Gymnastics is an education that starts from childhood and prepares them for war and provides order. Those who try again in all their jobs and remain qualified at the age of 50 devote most of their time to philosophy. Those go straight can have a good body, but not otherwise. Dialectic and gymnastics are seen as equivalent but the subject is conditional (Plato et al., book VII 539e, 1991, p. 219). The subject is selected consonant with a defined axis of thought. The dialectic method is necessary to achieve the principles, the goal is to identify with the ideal. Some situations in which dialectics does not problematize determine its boundaries.

In the late 20th century narratives, the dialectical contradiction in the negative dialectic of Theodor W. Adorno is in search of the coexistence of different ones. "Dialectical contradiction "is" not simply: it means - it has the subjective significance - that it cannot be talked out of this. In this meaning, this intention, dialectics aims at what is different" (Adorno, 2007, p.153). There is no attempt to identify with any side of the binary, but the contradictory relations of the binary oppositions have endless productivity with the unrestrained dialectic. The contradiction has the potential to reveal alternative patterns through mediation as a provider of a critical environment. The contradiction between immanent meanings points to the insolubility of something. Unlike platonic thinking, dialectic is not a method because it does not harbor identity, it promotes contradiction. Resists harmonious, flowing attempts. The reason for dialectics is not the impulse of thought to regulate, in other words, not to reach a solution, but to an unreconciled, contradictory issue (Adorno, 2007) (Figure 2).

In Triton, the story takes place in Earth, Mars and in Triton which is one of the outer satellites. There is a war between the Inner Worlds (Earth and Mars) and the Outter Satellites, and we can imagine that this war symbolizes the binary opposition of the Inner Worlds and the External Satellites. Although Mars is classified as inner worlds, it has a softer form of governance than the authoritarian attitude of Earth, and is a transition between outer satellites and Earth (Delany, 2013). If we read fiction through binary opposition, Earth may represent one pole and Triton (representing outer satellites) may represent the other pole. While Mars is objectively belonging to the inner worlds, it can be considered as an essence derived from binaries. When analyzed in depht, in Earth, men are forbidden to prostitute, women are legal, whereas in Mars, the situation is the opposite. There is an exact contrast between Earth and Mars, but Mars has been placed in the category of inner worlds with objective attribution. The relations spread to all the fiction over the dialectic contradiction of inner worlds/outer satellites in a complex and ambiguous manner.

A similar attitude is also read through the unlicensed sector $(U 1)$. The unlicensed sectors which is located each city Satellite city had set aside a city sector where no law officially held-since, as the Mars sociologist who first advocated it had pointed out, most cities develop, of necessity, such a neighborhood anyway. These sectors fulfil ed a complex range of functions in the cities'psychological, political, and economic ecology... Most places in the unlicensed sector are statistically safer than the rest of the city" (Delany, 2013, p.30-31). The fact that a region without prohibitions is more secure than other regions shows a stance against the authorities, on the other hand, the fact that these regions have not spread to the whole city emphasizes the necessity of a certain authority. The Mars sociologist's advocacy for the the unlicensed sector $(U 1)$ is also a reference to the soft relationship between the outer satellites and of the outer satellites could be considered as a metaphorical reference to the authorities. "At founding, each Outer Mars. These ambiguous and complex situations create a heterogeneous environment by coexisting. 


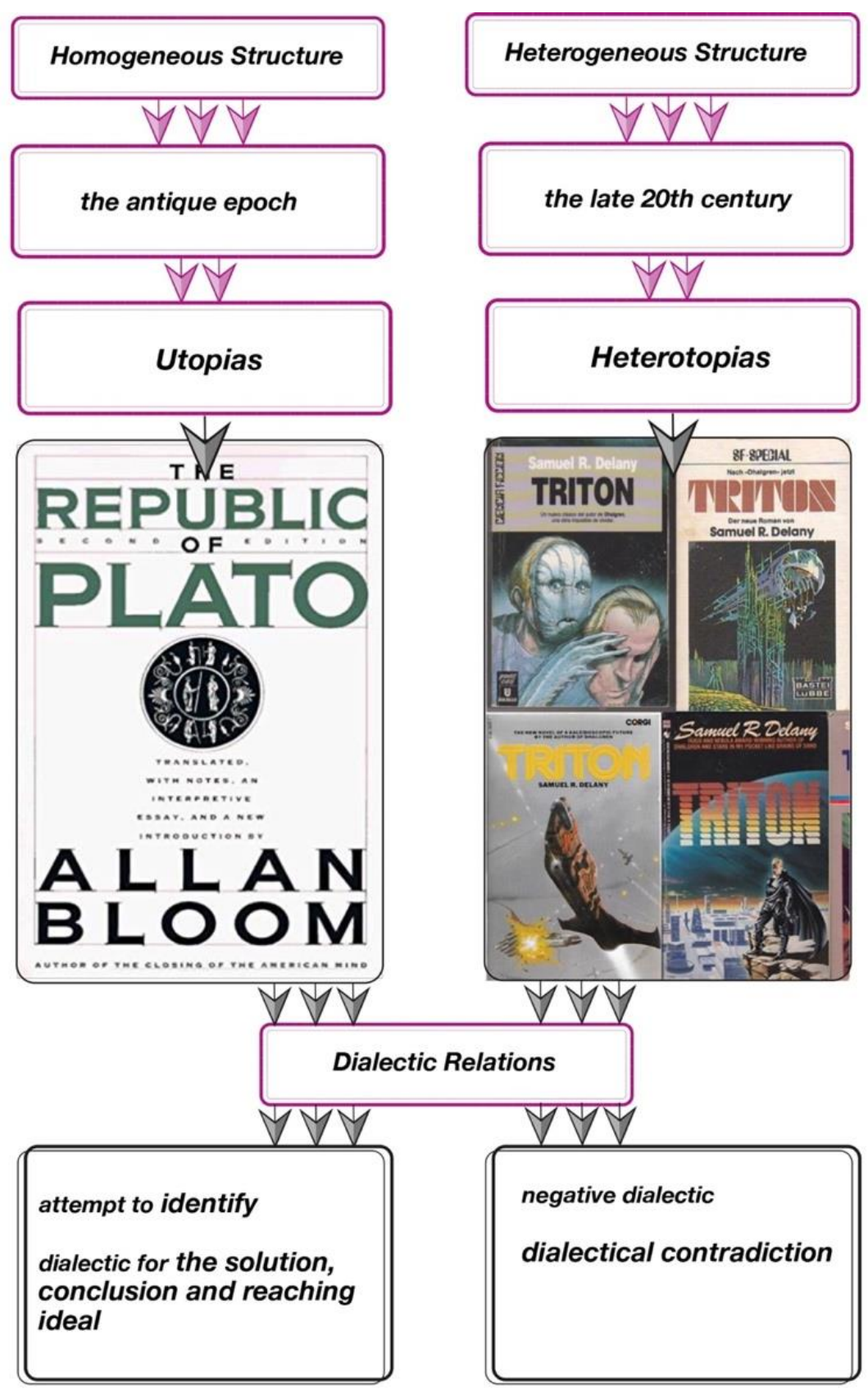

Figure 2. The narrative of the antique epoch The Republic of Plato, the narrative of the $20^{\text {th }}$ century Triton and their dialectical relations (diagram by author)

\subsection{Binary Opposition of Sex/Gender}

In the late twentieth century, the debate on the differences, relativity issues and racial, class and gender formations that existed in response to colonialism and capitalism (identity politics) were intensified. When Ann Oakley describes the sex notion as an biological differentiation she highlihts the necessity of the notion of gender as a psychological and cultural value that can change from one society to another (Oakley, 1972). Gender discourse criticizes the limitations of sex discourse and inequality in power relations. Haraway elaborates gender discourse as,

"Feminist accountability requires a knowledge tuned to resonance, not to dichotomy. Gender is a field of structured and structuring difference, in which the tones of extreme localization of the intimately personal and individualized body, vibrate in the same field with global high-tension emissions." (Haraway, 1988, p. 588)

In this case, it could be consulted to the productivity of the sex/gender binary opposition in order to go beyond the binaries and create resonances (Figure 3). 


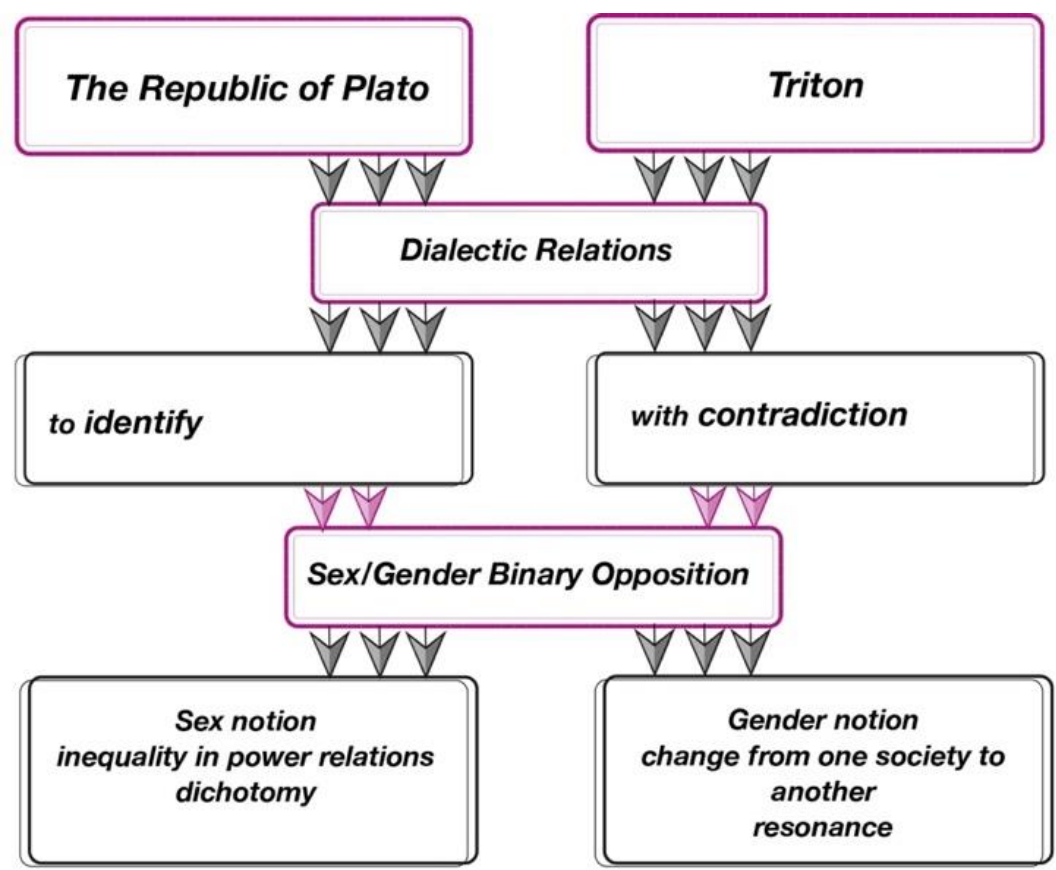

Figure 3. Sex/gender binary opposition and forms of dialectics

In the text of Triton, co-ops were constructed as the place of daily life and accommodation. co-ops vary according to gender and sexual preference (ambiguous preferential female co-ops or ambiguous preferential mixed co-ops with the combination of heterosexual-gay-mixed-one-indeterminate, etc.). Each co-op has a specific name (Serpent's House etc.). Co-ops with this attitude in the fiction destroys the conflict between sex/gender binary opposition and symbolize the unity, polyphony and originality. Another binary fall within regeneration and refixation treatments (to have somebody sexuality refixed on someone or thing, gender reassignment, having different sexual orientations, recovery old age effect on sexuality, etc.). These treatments and the free environment in which everything can be experienced eliminated the problematic of biological separation (sex). Lawrence is one who thinks these treatments should be avoided. On the other hand, the Spike (by definition of political homosexual for Lawrence) cannot understand those who do not make use of these treatments (Delany, 2013). They are representatives of two opposite poles.

The Spike:

“...I have very little sympathy with political homosexuals... I mean not only do we live in an age of regeneration treatments; there are refixation treatments too. He can have his sexuality refixed on someone, or thing, that can get it up for him... Sexual point-proving is such a waste of time..." (Delany, 2013, p.220222).

Bron who has close links with Lawrence and the Spike is in search of self among these poles. According to Bron, the Spike is too fixed-minded, and towards the end of story, he tries to gender reassignment and be a woman by dissenting from the attitude of Lawrence. With this stance, Bron represents neither Lawrence's attitude nor the Strike's attitude, She/he represents a complex attitude in between these represented poles that is differentiated from the binary opposition. While in some parts of the story, she/he is described as a rude person who cannot be get rid of the Mars identity; in other parts, is described as someone who has tried many things with the motivation of self-search. Fiction, which emphasizes gender discourse and focuses on the phenomenon of life, constructs the heterogeneous environment that it is represented and is mediated by fiction.

In the antiquity, the Greeks called the position of reflecting the way of being for the subject through her / his body (clothing, attitude, reactions, etc.) as ethos. In order to become an ethos, it is necessary to have freedom, to be good and ethical in the light of determined principles. In this case, the condition of ideal relationship is the practice or ethic of care. When Foucault focuses on the problematic of subjectivity/truth, he associates the practice of freedom to the practice of the self which was argued frequently in the ancient epoch. In Greek-Roman civilizations, the care of the self is at the core of social and individual life, in the sense of self - recognition from the point of the subject. In the 
Platonic movement, the practice of freedom is the truth which is necessary to reach the ideal one thereby the ethics itself (Fornet-Betancourt, Becker, Gomez-Müller \& Gauthier, 1987). This statement may be read on the specific part of The Republic of Plato which is argued about which kind of women are sufficient for the governance as women guardians. For women guardians, the condition of being women who have the care of the self and moral is basic. Regarding marriages, it is decided that the best of both sexes should be the most abundant and the worst ones should be the least about mating. Besides, only the children of the best are raised. After completing the age of giving birth to children for the republic, they will be free to mating with who they want (Plato et al., 1991, p. 135-141).

In the narrative of The Republic of Plato, the sex discourse is apparent in comparison with Triton and and ethics, self practices that match the ideal at the heart of the debate. There is a little level of eluding from sex discourse, but eventually there is a superiority of man. The discussion about whether or not the woman is able to perform the work that the man is performing, is carried out through dialogues.

"But if they look as though they differ in this alone, that the female bears and the male mounts, we'll assert that it has not thereby yet been proved that a woman differs from a man with respect to what we're talking about; rather, we'll stili suppose that our guardians and their women must practice the same things." (Plato et al., book V 454e, 1991, p.133)

The superiority of man remains on the agenda, although there is an emancipation of the sex discourse to a certain extent.

\section{Conclusion}

In the utopia of The Republic of Plato belongs to ancient epoch, it is aimed at reaching the ideal one through dialogues with the ethic of care for the self. The method of designing principles is dialectical, but the predefined truth is the limiter of dialectics. This shows that dialectics and principles meet certain limits. The aim of dialectics is to reach a conclusion and to reach the solution as the ideal.The formations that have been transformed in the historical perspective and lasted until the 20th century, draw attention to the limitedness of the notion of utopia in an attempt to construct a critical, multifarious environment by moving away from utopian attitude that is aspiring the ideal one. It underlines the need for new environments and models. The tension of sex/gender center focus of the epoch queries the content of gender discourse against integrated identities. The contradiction to the meanings constructs a multifarious, heterogeneous structure that goes beyond the binary of sex/gender discourse with the help of dialectics. Dialectical thought differs from the result-oriented dialectic which has the aim of identifying in the Platonic thought system, it is fragmentized and reconstructed by the help of contradiction. At this point, the dialectical contradiction has a potential to unlimited productivity. In parallel, the sex/gender dialectic focuses on constructing a heterogeneous structure in the late 20th century narratives while establishing a homogeneous structure in the utopian manner.

\section{References}

Adorno, T. W. (2007). Negative dialectics. Trans. by E.B. Ashton. New York: The Continuum International Publishing Group.

Delany, S. R. (2013). Triton. London: Gateway. Retrieved from https://play.google.com/books/reader?id=ORNKAQAAQBAJ\&hl=tr\&lr=\&printsec=frontcover\&pg=GBS.PP1

Fornet-Betancourt R., Becker H., Gomez-Müller A., \& Gauthier J.D. (1987). The ethic of care for the self as a practice of freedom: an interview with Michel Foucault on January 20, 1984. Philosophy \& Social Criticism, 12(2-3), 112 131. doi:https://doi.org/10.1177/019145378701200202

Foucault, M. (2005). The Order of Things. London: Routledge. doi:https://doi.org/10.4324/9780203996645

Haraway D. (2006) A Cyborg Manifesto: Science, Technology, and Socialist-Feminism in the Late 20th Century. In: Weiss J., Nolan J., Hunsinger J., Trifonas P. (eds) The International Handbook of Virtual Learning Environments. Dordrecht: Springer. doi:https://doi.org/10.1007/978-1-4020-3803-7_4

Haraway, D. (1988). Situated Knowledges: The Science Question in Feminism and the Privilege of Partial Perspective. Feminist Studies, 14(3), 575-599. doi:https://doi.org/10.2307/3178066

Harding, S. G. (1986). The science question in feminism. Ithaca: Cornell University Press.

Moles A. (2012). Belirsizin bilimleri. Trans. by N. Bilgin. İstanbul: Yapı Kredi Yayınları.

Oakley, A. (1972). Sex, gender and society. London: Temple Smith.

Plato, \& Bloom, A. (1991). The Republic of Plato. New York: Basic Books. 